\title{
Self-Regulatory Efficacy and Mindset of At-Risk Students: An Exploratory Study
}

\author{
Ian A. Matheson \\ Queen's University
}

\begin{abstract}
There is a limited body of research examining how students' beliefs about intelligence and about their abilities relate to different learning environments. As reported here, I examined secondary school students' beliefs, goals, and expectations guided by Zimmerman's (2000) model of self-regulated learning. In this exploratory study, 230 secondary school students reported on their beliefs about learning and intelligence, as well as on their confidence in their self-regulatory abilities. I made comparisons between groups of students on beliefs, goals, and expectations based on their school stream, achievement, learning disability status, and gender. Both self-regulatory efficacy and reading mindset were significantly different for students based on their school stream and their achievement level. The findings of this exploratory study suggest a need for further research that focuses directly on whether at-risk students demonstrate maladaptive motivation and specifically on their beliefs, goals, and expectations of themselves as learners.
\end{abstract}

While some students thrive in high school, others are described as at risk for dropping out. Educators use the term at risk to describe students who demonstrate poor achievement, personal problems such as social maladjustment, and overall disengagement from school (DeLuca et al., 2010). Secondary schools often use streaming in order to meet diverse students' needs (e.g., Ontario Ministry of Education, 2007). Students' past school achievement is a major influence on the stream that they choose for courses in secondary school, resulting in at-risk students typically enrolling in what are described as "applied streams." 
Research has consistently supported a relationship between achievement and motivation (Baird, Scott, Dearing, \& Hamill, 2009; Blackwell, Trzesniewski, \& Dweck, 2007; Yeager \& Dweck, 2012). Motivation refers to the driving force behind actionwhat motivates us influences our actions toward goals that we set (Pintrich \& Schunk, 2002). Aspects of motivation include our beliefs, goals, and expectations of ourselves (Dweck, 2006). More specifically, these aspects of motivation include how we understand intelligence, the types of goals we set, how we make sense of our successes and failures, and our expectations of ourselves. These constructs can be considered together as aspects of motivation, as they may help to regulate the quality of our actions, including the amount of effort we put into various tasks and activities to reach goals that we have set (Baird et al., 2009; Blackwell et al., 2007). This research suggests that at-risk students may differ in these sources of motivation from their peers. Because at-risk students are characterized by low achievement, and achievement appears to be related to motivation, I designed this study to explore whether at-risk students enrolled in applied programs demonstrate maladaptive motivation. This issue appears to have been overlooked in the research on motivation, prompting the need for exploratory research.

For nearly three decades, researchers have examined how students manage their learning and motivation in order to meet learning goals (e.g., Zimmerman, 2008). This process of self-regulated learning (SRL) is thought to contribute to academic success. For example, Zimmerman (2000) proposed a three-phase cyclical model of SRL that incorporates aspects of motivation before, during, and after performance on a task.

Although many variables associated with schooling have been investigated, there do not appear to be any studies related to SRL that have included secondary students' placement in a stream. School subjects are often divided into various streams designed partially to address students' needs as learners. To use English courses in Ontario as an example, students in Grades 9 and 10 can choose the Academic, Applied, or Essential streams. Students in Grades 11 and 12 can choose among University, College, or Workplace streams (Ontario Ministry of Education, 2007). The titles of these streams demonstrate how educators see them as leading students in different directions upon completion of their secondary school career.

As in other jurisdictions, applied courses in Ontario are designed to examine the essential concepts of subjects, while academic courses deal with more abstract and theoretical constructs in these subjects (Ontario Ministry of Education, 2011). Students who take applied-level courses typically move into the college stream, which is designed to provide students with the necessary skills for college or an apprenticeship; and students in the academic stream typically move into the university stream, which is designed to prepare students for a university setting (Ontario Ministry of Education, 2011).

At-risk youth are rarely found in academic stream courses and tend to demonstrate low achievement no matter what stream they are in (DeLuca et al., 2010). Informed by Zimmerman's (2000) model of SRL, the present exploratory study aims to contribute to the literature on motivation by including school stream in an examination of aspects of motivation related to SRL. 


\section{Self-Regulated Learning}

Students are considered to be self-regulated learners based on the degree of their active involvement in their own learning (Effeney, Carroll, \& Bahr, 2013). SRL is a process that involves planning and the use of strategies and monitoring to guide behaviour toward learning goals set by the learner (Ilkowska \& Engle, 2010). Learners must actively represent the standard or goal that they wish to reach in their mind, after which they must plan and implement strategies they believe will help them to reach their goals (Hofmann, Schmeichel, \& Baddeley, 2012).

Zimmerman (2000) proposed a three-phase cyclical model of SRL that distinguished between learners' thinking prior to beginning a task, while engaged in the task, and after engaging in the task. Prior to beginning a task, learners are in the "forethought phase," which is characterized by the setting of different types of goals as well as by learners' beliefs about their abilities. While engaged in the task, learners are in the "performance phase," which involves working on the task and monitoring progress throughout the task. After engaging with the task, learners are in the "self-reflection phase," which involves their own evaluation of their performance and making conclusions about why they performed the way that they did.

In Zimmerman's (2000) model, learners' beliefs, goals, and expectations are acknowledged as influences on the SRL process. These factors are relevant within the pre- and post-task stages as learners prepare to engage in a task and reflect on their performance after engaging with the task. Schraw (2010) distinguished between "online" and "offline" measures of SRL, referring to the difference between measures that examine SRL during the learning episode and those that measure it before or after, as in the pre- and post-task stages of Zimmerman's model. Distinctions can be made among stages of SRL based on their relation to the primary learning episode. Online stages would be those that characterize activity during engagement with a task, whereas offline stages include those that take place either before or after engagement with a task. Given this distinction, learners' beliefs, goals, and expectations can be considered as "offline variables related to self-regulated learning," or "offline variables" for brevity in this paper. According to models of SRL (e.g., Zimmerman, 2000), online and offline variables together contribute to the success that students experience when learning. The current study focuses on offline variables related to SRL.

\section{Offline Variables Related to SRL}

As educators recognize that students come to them with different backgrounds and with varying abilities, they work to differentiate their teaching to accommodate all types of learners, and to create inclusive classrooms (Hutchinson, 2014). Sometimes the supports are in place for students' learning, but individual differences in how students think about themselves and their abilities can limit personal growth and development (Yeager \& Dweck, 2012). Individuals may hold beliefs about how malleable human qualities are as well as about the potential for growth and change to occur. These implicit beliefs are sometimes referred to as mindsets, and can include beliefs about social characteristics as well as intellectual abilities (Dweck, 2006). In the case of students within a classroom, mindsets may have an influence on how students respond to adversity 
that they face and may allow some students to thrive while others flounder. Besides the beliefs we endorse about the nature of learning and intelligence, our experiences in life lead us to develop varying levels of confidence in our own abilities as learners within our environment (Blackwell et al., 2007; Klassen, 2010).

In her work related to motivation and mindset, Dweck (2006) proposed that implicit theories of intelligence may set up a system of beliefs, or a mental framework, that involves how we think about our experiences. If this mental framework is set up by beliefs about the nature of qualities as fixed or malleable, it will likely influence the types of goals students set for themselves, as well as their attributions for their successes and failures. Students with a "fixed mindset" believe that we are born with a certain amount of intelligence and ability and that we can do very little to change that. When students with a fixed mindset believe that they are not able to be successful at a task, their goals are focused on hiding their inability from others. Given their belief in the fixed nature of ability, little effort will be made to improve their abilities, or to challenge themselves, or to persist when a task becomes difficult. Students with a "growth mindset" believe that our abilities and intelligence can grow. Challenge and difficulty are viewed as necessary ingredients for the growth of intelligence and ability, and students with growth mindsets set goals that are focused on learning rather than on how well they will do or what others will think of them (Dweck, 2006).

Consistent with fixed and growth mindsets, distinctions can be made between mastery and performance goals, as well as avoidance and approach goals (Elliot \& McGregor, 2001). Mastery goals are concerned with personal growth and task mastery, whereas performance goals are focused on the demonstration of competence. Learners who set mastery-approach goals aim to engage in a task with the hope of mastering it. Learners who set performance-avoidance goals aim to avoid engaging with a task; they hope to avoid looking incompetent in front of their peers. Recent research on achievement goals indicates avoidance-oriented goals are related to low academic achievement, and approach-oriented goals are related to high achievement (e.g., Huang, 2012).

According to Dweck (2006), fixed and growth mindsets translate into entity and incremental theories of intelligence respectively. In one investigation, researchers found evidence to support the idea that implicit theories of intelligence set up the types of attributions students make for their successes and failures in post-secondary settings in both eastern and western cultures (Hong, Dweck, Chiu, Lin, \& Wan, 1999). In contrast to the view that intelligence is central to achievement and learning, which is typical of western cultures (Tweed \& Lehman, 2002), Chinese students seemed to view intelligence as distinct from school performance and place a higher value on effort, which is often the case in eastern culture (Wang \& Ng, 2012). Chen and Pajares (2010) pointed out the need for more research examining variables related to self-efficacy within Dweck's socialcognitive model.

In addition to beliefs about the potential for growth, the types of goals we set, and our attributions for success, Zimmerman's (2000) model of SRL included self-efficacy. Self-regulatory efficacy refers to an individuals' confidence in their ability to selfregulate. Self-regulation includes managing distractions, maintaining focus on the task, 
and meeting goals that have been set. Students with high self-regulatory efficacy have likely had past success with the subject area, and therefore feel that they have the skills and ability to achieve success again. Students with low self-regulatory efficacy have likely not experienced past success in the domain area, and may feel unsure about which strategies to use or perhaps even give little effort, with a lack of belief in their likelihood of achieving success. Taken together, the variables that make up mindset, along with selfregulatory efficacy, can be considered as offline variables related to SRL within Zimmerman's (2000) model of SRL.

\section{Offline Variables and Achievement}

Past research has shown that offline variables and achievement are related. For example, endorsing an entity theory of intelligence, having a preference for performance goals, attributing success to ability rather than effort, and having low confidence in one's ability to self-regulate are all associated with lower achievement (e.g., Baird et al., 2009). One study showed that the natural decline in grades slowed for incremental theorists compared to their entity theorist counterparts during the Grade 8 transition (Yeager \& Dweck, 2012). Blackwell et al. (2007) conducted a longitudinal study and found that students' initial theories of intelligence were significant predictors of mathematics achievement, and that an incremental theory of intelligence was significantly correlated with learning goals, beliefs about effort, and beliefs about ability, as well as with attributions and strategies for handling setbacks. In another investigation, researchers found evidence that endorsing an entity theory of intelligence predicted lower scores on IQ tests (Cury, Da Fonseca, Zahn, \& Elliot, 2007).

Dupeyrat and Marine (2005) conducted a study that tested and extended Dweck's social-cognitive theory of motivation using adults returning to school. They found that implicit theories of intelligence were not significantly related to the types of goals students endorsed or to their achievement. In a study of elementary and junior-highschool students from Greece, the researchers did not find a relationship between implicit theories of intelligence and academic achievement, and also found that goal orientations had an indirect effect on achievement (Leondari \& Gialamas, 2002). Despite these mixed results, researchers in motivation tend to argue that an entity view of intelligence, the endorsement of avoidance-oriented goals, and a belief that ability is more important than effort all should be considered maladaptive given findings on the strength of their negative relationship with performance (Baird et al., 2009; Blackwell et al., 2007; Hong et al., 1999; Huang, 2012).

Though mixed evidence exists concerning the relationship between mindset and achievement, the relationship between self-regulatory efficacy and achievement seems to be clearer. Students' self-regulatory efficacy has been found to positively relate to achievement and motivation in diverse academic areas and at all levels of schooling (Pajares, 2007). More specifically, Klassen (2010) found that self-regulatory efficacy was related to students' final English grades. 


\section{Offline Variables and Learning Disabilities}

Exceptional learners in Canada are students who have been recognized as needing support systems in addition to what is already provided to most students (Hutchinson, 2014). Learning disabilities (LD), for example, affect students' ability to process information during tasks such as reading and writing, and are likely linked to neurological or cognitive deficits (Hallahan, Pullen, \& Ward, 2013). Support systems for exceptional learners, including students with LD, can include accommodations such as additional time or scribing, as well as placement in alternative learning settings such as a resource room (Ontario Ministry of Education, 2004). Students with LD may feel that there are limitations on their learning, given their difficulties with information processing (Baird et al., 2009).

Research has emerged concerning the differences between the academic achievement of students with and students without learning disabilities (LD), though less attention has been directed at differences between these groups specifically in selfregulatory efficacy and other offline variables (Baird et al., 2009; Klassen, 2010). Baird et al. (2009) found that youth with LD were more likely than their non-LD peers to possess a maladaptive cognitive self-regulatory pattern, consisting of an entity theory of intelligence, a preference for performance goals, a tendency to make ability attributions, and a lower score in academic self-efficacy. In a 2010 study, Klassen found that students with LD had lower self-regulatory efficacy ratings than their peers without LD.

This research suggests that students with LD often have low self-regulatory efficacy, and that self-regulatory efficacy is related to final grades in English for students both with and without LD (Baird et al., 2009; Klassen, 2010). Including measures of other offline variables along with self-regulatory efficacy in the same study can provide a clearer picture of the relationships among these variables. Also, making comparisons between groups of students with and without LD allows the differences between these two populations to be better understood. These studies also help to establish a possible relationship between aspects of self-efficacy and mindset, which should be further explored together in research with students with LD.

\section{Offline Variables and Gender}

In considering how expectations are related to motivation and SRL, it is important to also consider gender. Some research supports the idea that women take others' opinions of them more seriously than men do (Dweck, 2006). There is also a large amount of support for the gender gap in literacy, where females typically outperform males in reading and writing (Williams, 2006). In one study, Siegle, Rubenstein, Pollard, and Romey (2010) found that males seemed to report higher perceived ability than females in almost all subject areas. In the same study, the researchers found that males believed that natural ability is more important for achievement in Language Arts, and that males were more likely than females to attribute their successes to ability, whereas females were more likely to attribute their successes to effort. In contrast to the reported findings on males' greater confidence in their ability for school subjects, one study suggested that females report higher confidence in their ability to self-regulate than males (Usher \& 
Pajares, 2008). Much of the research related to mindset and gender focuses on math and little on literacy (e.g., Blackwell et al., 2007).

\section{Offline Variables and School Stream}

Students' choices of the streams they will enter in secondary school may be heavily influenced by their past achievement in each subject. Teachers often recommend a stream to each student and their guardian(s), which may be based on their past achievement, among other things. For this reason, the empirical evidence to support a difference in motivational variables based on achievement (e.g., Blackwell et al., 2007; Baird et al., 2009) suggests that there may also be differences in offline variables between students in different streams.

It is important to examine the literature surrounding offline variables related to SRL within specific contexts (Hammer \& Elby, 2002). Dweck (2006) suggested that mindset can vary in different subject areas, though little research has been conducted to test this claim, and some evidence exists that it may not differ between subjects (Stipek \& Gralinski, 1996). Similarly, the way students conceptualize learning and intelligence may vary between learning environments (e.g., Trautwein \& Ludtke, 2007a). It has been suggested that students may learn to view knowledge from the same perspective as those around them, sometimes known as the enculturation process (Jehng, Johnson, \& Anderson, 1993). One could consider that students who spend time together in the same classes based on academic stream may start to conceptualize learning, intelligence, and their abilities in similar ways. Additionally, students may receive implicit messages from their instructors, or even from the classroom environment and climate, that can affect their motivation (Ommundsen, 2006). Given the differences between the various streams in pace and depth (e.g., University English and College English in Ontario), it is plausible that teachers may have different expectations of the students based on the stream. In one study, the researchers found that stereotypes about the abilities of certain groups may have an effect on the motivation of students who belong to these groups (Aronson, Fried, \& Good, 2002).

The type of learning environment that exists within a classroom seems to have some influence on students' motivation, and it could be argued that different elements of offline variables may even cause students to pursue different subject areas or academic paths (Trautwein \& Ludtke, 2007b). Students within the college stream may feel that they are not as intelligent as their peers in the university stream. Also, students in the college stream may feel that their abilities or intelligence will not grow to the level of their peers in the university stream, and they have therefore been placed on a different path. Besides the need for research to continue to examine mindset by learning environment, researchers should also look at how self-regulatory efficacy is related to learning environment given its relationship to achievement (e.g., Usher \& Pajares, 2008).

\section{The Present Study}

Research suggests that implicit theories of intelligence may be related to selfefficacy and achievement, although this relationship seems to have been studied primarily in mathematics (Blackwell et al., 2007; Davis, Burnette, Allison, \& Stone, 2011; Rattan, 
Good, \& Dweck, 2012). It appears that an individual's beliefs about intelligence contribute to a system of other beliefs, including attributions individuals make about effort and ability (Hong et al., 1999). Students with LD seem to be more likely to endorse a fixed mindset than their non-LD peers, and they typically report lower scores in selfefficacy and self-regulation than their peers (Baird et al., 2009; Klassen, 2010). Lastly, while more research is needed regarding gender and offline variables, males seem to attribute success in academic areas more often to ability, while females seem to make attributions more frequently based on effort (Siegle et al., 2010).

In the present study, I examined the differences among students in terms of their beliefs, goals, and expectations - all considered to be offline variables related to SRL. I made comparisons based on students' English stream, LD status, achievement level, and gender. I aimed to validate existing research on gender, LD status, and achievement, as well as to extend past research by examining how offline variables relate to course stream. This research is important for education, as it can give us a better understanding of the characteristics of students in the various streams that characterize secondary education in Canada, the United States, and Europe. To date, there is a paucity of research examining offline variables related to SRL of students within the various school streams in secondary schools. This information may enable educators to meet the needs of those students. The research questions that guided the present study are:

1. How do students in different streams differ in their beliefs, goals, and expectations?

2. Is there a difference in students' beliefs, goals, and expectations by LD status?

3. How do students at four levels of achievement differ in their beliefs, goals, and expectations?

4. Is there a difference in students' beliefs, goals, and expectations by gender?

\section{Method}

\section{Context and Participants}

A total of 230 secondary school students (117 male, 113 female) from one rural school in southeastern Ontario, Canada, participated in this study. The school of 1,200 students has a strong and accessible resource program to support student needs, and is situated in a community with very few visible minorities. Prior to conducting the study, I worked in the school in a remedial literacy program with Grade 9 and Grade 10 students, and observed actions consistent with the school's public commitment, on its website, to fully engage students and improve achievement through "individual student programming" and the provision of strong and accessible resources "addressing a full range of academic abilities." Each participant was enrolled in either their third or fourth compulsory English credit of the university or college stream. Each of these classes included students enrolled in Grade 11 and Grade 12, who would typically range from 16 to 18 years of age. I collected data during a time of job action by teachers in Ontario; the only school that agreed to participate in the research set strict conditions on how the study would be conducted. In order to obtain teacher agreement to participate, the school 
administration placed limitations on the amount and nature of data that could be collected and on the amount of time that I could be in the classrooms. The administration did not allow me to access student records, which would have included current age and grade; I was forced to ask students to self-report demographic information and asked only for their gender, LD status, and recent achievement in addition to their responses to the offline variable measures.

Of the 230 participants, 38 indicated that they had been identified as having LD, while the remaining 192 indicated that they had never been identified as having LD. Given the age range of the students, it is reasonable to expect they would know if they had experienced the identification process for LD in Ontario. The identification process in Ontario consists of the gathering of pertinent information, the establishment of a team to support the student, the development of an Individual Education Plan (IEP), and the implementation of the IEP in relevant contexts within the school (Ontario Ministry of Education, 2004). Currently in Ontario, the identification of LD is based on the documentation of a discrepancy between ability and achievement for students who have average or better intelligence (Ontario Ministry of Education, 2001) despite researchers' criticisms of the use of this discrepancy formula (e.g., Stanovich, 2005).

\section{Measures}

Demographic information. I collected demographic information for all participants, using three items designed to allow me to group participants for further analysis. The first item asked participants to indicate their gender. The second item asked participants to indicate whether or not they had been diagnosed with a learning disability. The third item collected data on participants' achievement in English class, by asking students to indicate the grade they had received on the midterm report they had recently received. Based on the English class in which the participating students were enrolled, I recorded the level of their stream. I collected data during a period of job action by teachers within Ontario, and therefore collecting self-reported data on gender, LD status, and achievement in English class was the only feasible method for obtaining these data. As a result, data were not available on whether or not students with LD were receiving support.

Implicit theories of intelligence. I assessed students' implicit theories of intelligence using the Implicit Theories of Intelligence Scale for Children-Self Form (ITI; Dweck, 1999). This scale assessed the theory of intelligence that participants endorsed using three items. I modified the scale from a 6-point to a 5-point Likert scale $(1=$ strongly agree, $5=$ strongly disagree $)$ to simplify the wording on the scale with the intent of accommodating any difficulties students might have in comprehending instructions. The three items assessed whether participants viewed their intelligence as fixed or malleable. High scores on this scale indicate that an incremental theory of intelligence is more highly endorsed, consistent with the growth mindset. Despite being designed for children, this scale has been used in research with students ranging from grades 6 to 12 (Baird et al., 2009). In the present study, the Cronbach alpha was .86.

Learning vs. performance goal preferences. I assessed students' learning vs. performance goal preferences using the Learning vs. Performance Goal Preference Scale (Dweck, 1999), which consists of three items. As I had for ITI, I modified the scale from 
a 6-point to a 5-point Likert scale. The third item was reverse-scored to allow high scores to indicate a preference for learning goals, consistent with the growth mindset. In the present study, the Cronbach alpha for this three-item scale was .52. This scale was not included in the subsequent analyses because of its low reliability.

Effort vs. ability attributions. I assessed students' effort versus ability attributions using the Effort Attribution Scale (Dweck \& Leggett, 1988). This scale consists of two items that measured effort attributions of participants. Again, as I had for the previous measures, I modified the scale from a 6-point to a 5-point Likert scale, where higher scores indicated effort attributions consistent with the growth mindset. In the present study, the Cronbach alpha was .49. This scale was not included in the subsequent analyses as a result of its low reliability.

Self-regulatory efficacy. I assessed students' self-regulatory efficacy using the SelfEfficacy for Self-Regulated Learning Scale (Zimmerman, Bandura, \& Martinez-Pons, 1992). The original scale consists of 11 items. A 7-item version of the same scale was constructed and has been considered to be reliable and valid (Usher \& Pajares, 2008). The scale measured how confident students felt in their ability to self-regulate when engaging in academic activity. Participants responded on a 5-point Likert scale $(1=$ never, 5 = always). The present study used a modified version of the scale, with a total of eight items. Some research has suggested that there may be a difference in an individual's ability to meet self-imposed deadlines and other-imposed deadlines (e.g., Klassen, Krawchuk, \& Rajani, 2008), and, for this reason, an additional item addressing this difference was included. The additional item asked participants: "How well can you meet academic deadlines you set for yourself?" The internal reliability of the scale decreased when the additional item was removed, and therefore the inclusion of the additional item was warranted with the sample used in the present study. I again modified the ratings for the Likert scale to make them easier to read, in order to accommodate any difficulties students may have in comprehending instructions. Higher scores indicated that students had higher self-regulatory efficacy. With all eight items included, the Cronbach alpha for this scale was .82 .

English mindset. I used eight items to measure students' noncontingency, helplessness, and self-regulatory efficacy toward both reading and writing, given the English focus of the study. The noncontingency items measured students' perceptions of the amount of control they have over whether or not they can improve in the area, while helplessness items measured students' beliefs about whether or not they are helpless to improve in an area. The noncontingency and helplessness measures are a part of a 20item scale known as the Academic Ineffectiveness Scale, which has been used to measure academic self-concept in elementary school-aged children (Berg, 2001). While the language used in the scale is designed for children, it is appropriate for use with the diverse sample in the present study that likely included students with a wide range of reading abilities. The four self-regulatory efficacy questions measure an individual's confidence in their ability to self-regulate when engaging in either reading or writing. I reverse-scored items so that a higher score in English mindset (like a higher score in selfregulatory efficacy) was consistent with the growth mindset. Four of the eight items reflected reading mindset, and four items were designed to reflect writing mindset. In the present study, the Cronbach alpha for this 8 -item scale was .40 . I removed two items 
from the scale, one for reading and one for writing, based on low correlations with the other items; and the Cronbach alpha improved to .66. Thus the 6-item scale was retained for subsequent analyses.

\section{Procedures and Analyses}

I visited all English classes within the academic and applied streams that were either the third or fourth compulsory English credit. In each class, I gave a five-minute presentation to inform students about the purpose and nature of the study. I informed students that the questionnaire was anonymous, voluntary, and that it was composed of questions about mindset and motivation, as well as about their ability to manage their learning environment. The compulsory English credit courses last for one semester, and so I collected data at two points during the school year, once during each semester from a different set of students. After two weeks, to allow students time to consider participating in the study, I provided all willing participants who had returned letters of consent with a copy of the questionnaire to be completed during their English class. Those students who had volunteered to be a part of the study completed the questionnaire either at the beginning or end of class, depending on the teacher's preference, while their peers engaged in silent reading until all questionnaires had been collected. On average, students took 10 minutes to complete the questionnaire. Collecting data in both fall and spring semesters enabled me to recruit the target number of participants. Data collection took place within two weeks after the midterm reports had been delivered to students, to ensure they could remember and report their recently received midterm mark when completing the questionnaire.

I analyzed data using IBM SPSS Statistics 21. Eight participants had missing data. Pair-wise deletion was used for one student who had incomplete data for the entire selfregulatory subscale, though complete data on other variables were used for other analyses. One student was missing data for one item in the self-regulatory efficacy subscale, and the mean score for the entire sample for this one item was substituted for the missing data in this case. Six students had missing data for one item in the reading portion of the English mindset subscale, and the mean score for the entire sample for this one item was substituted for the missing data. Both positively and negatively keyed items were present in the questionnaire; therefore negatively worded items were reverse-scored.

For achievement level, I split students into four groups based on their midterm English grades regardless of stream. Groups had scores that were $80 \%$ and above (A), from 70 to $79 \%$ (B), from 60 to $69 \%$ (C), and below $60 \%$ (D) to reflect the four recognized levels of achievement in the Ontario Secondary School English curriculum (Ontario Ministry of Education, 2007).

\section{Results}

Means and standard deviations for all variables can be seen in Tables 1 to 4, organized by school stream, LD status, achievement, and gender, respectively. Table 5 provides correlations between pairs of variables including gender, learning disability status, stream, achievement, theories of intelligence, self-regulatory efficacy, and English mindset. 


\section{Table 1}

Summary of Group Differences by School Stream

\begin{tabular}{lcccc}
\hline Variables & \multicolumn{2}{c}{$\begin{array}{c}\text { University } \\
(n=129)\end{array}$} & \multicolumn{2}{c}{$\begin{array}{c}\text { College } \\
(n=101)\end{array}$} \\
\hline \multirow{3}{*}{ Gender } & $M$ & $S D$ & $M$ & $S D$ \\
LD Status & 0.53 & 0.50 & 0.48 & 0.50 \\
Achievement & 0.08 & 0.27 & 0.28 & 0.45 \\
ITI & 0.83 & 0.93 & 1.22 & 0.99 \\
SRE & 10.16 & 3.35 & 9.63 & 3.09 \\
EM & 28.40 & 5.87 & 25.93 & 5.74 \\
\hline
\end{tabular}

Table 2

Summary of Group Differences by LD Status

\begin{tabular}{lcccc}
\hline Variables & \multicolumn{2}{c}{$\begin{array}{c}\text { LD } \\
(n=38)\end{array}$} & \multicolumn{2}{c}{$\begin{array}{c}\text { NLD } \\
(n=192)\end{array}$} \\
\hline \multirow{3}{*}{ Gender } & $M$ & $S D$ & $M$ & $S D$ \\
English Stream & 0.53 & 0.51 & 0.51 & 0.50 \\
Achievement & 0.26 & 0.45 & 0.62 & 0.49 \\
ITI & 1.34 & 0.88 & 0.93 & 0.98 \\
SRE & 10.92 & 3.18 & 9.73 & 3.22 \\
EM & 25.92 & 6.45 & 27.58 & 5.79 \\
& 14.11 & 2.29 & 14.12 & 2.28 \\
\hline
\end{tabular}

Table 3

Summary of Group Differences by Gender

\begin{tabular}{lcccc}
\hline Variables & \multicolumn{2}{c}{$\mathbf{F}$} & \multicolumn{2}{c}{$\mathbf{M}$} \\
& \multicolumn{2}{c}{$(n=113)$} & \multicolumn{2}{c}{$(n=117)$} \\
\hline English Stream & $M$ & $S D$ & $M$ & $S D$ \\
LD Status & 0.53 & 0.50 & 0.59 & 0.49 \\
Achievement & 0.16 & 0.37 & 0.17 & 0.38 \\
ITI & 0.79 & 0.87 & 1.21 & 1.02 \\
SRE & 10.17 & 3.28 & 9.69 & 3.19 \\
EM & 28.12 & 5.13 & 26.51 & 6.54 \\
& 14.39 & 2.05 & 13.87 & 2.45 \\
\hline
\end{tabular}

Tables 1-3 note. Gender $($ Female $=0$, Male $=1)$, English Stream $(\mathrm{C}=0, \mathrm{U}=1)$, LD Status (NLD =0, LD = 1), Achievement $(A=0, B=1, C=2, D=3)$, ITI (range, 3-15; higher scores consistent with growth mindset), SRE (range, 8-40, higher scores indicate higher SRE), EM (range, 1-18, higher scores consistent with growth mindset). 
Table 4

Summary of Group Differences by Achievement Level in English

\begin{tabular}{lrrrrrrrr}
\hline Variables & \multicolumn{2}{c}{$\mathbf{A}$} & \multicolumn{2}{c}{ B } & \multicolumn{2}{c}{$\mathbf{C}$} & \multicolumn{2}{c}{$\mathbf{D}$} \\
$(n=90)$ & \multicolumn{2}{c}{$(n=68)$} & \multicolumn{2}{c}{$(n=54)$} & \multicolumn{2}{c}{$(n=18)$} \\
\hline \multirow{3}{*}{ Gender } & \multicolumn{1}{c}{$\boldsymbol{M}$} & $S D$ & $M$ & $S D$ & $M$ & $S D$ & $M$ & $S D$ \\
LD Status & 0.42 & 0.50 & 0.44 & 0.50 & 0.67 & 0.48 & 0.72 & 0.46 \\
English Stream & 0.08 & 0.27 & 0.21 & 0.41 & 0.26 & 0.44 & 0.17 & 0.38 \\
ITI & 0.68 & 0.47 & 0.53 & 0.50 & 0.46 & 0.50 & 0.39 & 0.50 \\
SRE & 10.36 & 3.24 & 10.21 & 3.22 & 8.89 & 3.17 & 9.83 & 3.11 \\
EM & 30.04 & 5.47 & 26.76 & 6.04 & 24.72 & 4.73 & 23.28 & 4.76 \\
\hline
\end{tabular}

Note. Gender $($ Female $=0$, Male $=1)$, LD Status $(\mathrm{NLD}=0, \mathrm{LD}=1)$, English Stream $(\mathrm{C}=$ $0, \mathrm{U}=1$ ), ITI (range, $3-15$, higher scores consistent with growth mindset), SRE (range, 8 40, higher scores indicate higher SRE), EM (range, 1-18, higher scores consistent with growth mindset).

\section{Preliminary Analyses}

The majority of participants came from the university English stream, with approximately 10\% fewer from the college English stream. As for the students with learning disabilities, the sample included a higher percentage of students $(16.5 \%)$ with LD than the $10 \%$ that were expected (Hutchinson, 2014). The distribution of participants by achievement included almost $40 \%$ in the A grade range, approximately $30 \%$ at the B level as the next highest percentage, followed by almost $25 \%$ in the $\mathrm{C}$ grade range and less than $10 \%$ in the $\mathrm{D}$ grade range. The sample had almost an equal number of males and females.

As shown in Table 5, enrolment in the College stream for English was associated with the self-identified presence of a learning disability $(r=-.27, p<.01)$, as well as a lower reported grade in English $(r=-.20, p<.01)$. Additionally, enrolment in the university stream for English was associated with higher self-regulatory efficacy $(r=.21$, $p<.01)$ and with a growth-oriented mindset in English $(r=.18, p<.01)$. Presence of LD was associated with a lower grade in English $(r=.17, p<.01)$, as well as the endorsement of an incremental theory of intelligence $(r=.14, p<.05)$, consistent with the growth mindset. Having a higher grade in English was associated with higher selfregulatory efficacy $(r=-.40, p<.01)$ and being a female $(r=.21, p<.01)$. Also, a higher grade in English was associated with the endorsement of an incremental theory of intelligence $(r=.14, p<.05)$ and a "growth" oriented mindset in English $(r=-.27, p<$ $.01)$. Being a female was associated with higher self-regulatory efficacy $(r=-.14, p<$ $.05)$. Finally, higher self-regulatory efficacy was associated with the endorsement of a growth-oriented mindset in English $(r=.49, p<.01)$. 


\section{Table 5}

Relations Among Independent Variables and Motivational Variables

\begin{tabular}{lcccccc}
\hline & $\mathbf{2 .}$ & $\mathbf{3 .}$ & $\mathbf{4 .}$ & $\mathbf{5 .}$ & $\mathbf{6 .}$ & $\mathbf{7 .}$ \\
\hline 1. English Stream & $-.27^{\star *}$ & $-.20^{* *}$ & .06 & .08 & $.21^{* *}$ & $.18^{* *}$ \\
2. LD Status & & $.17^{* *}$ & .02 & $.14^{*}$ & -.11 & -.00 \\
3. Achievement & & & $.21^{* *}$ & $-.14^{*}$ & $-.40^{* *}$ & $-.27^{* *}$ \\
4. Gender & & & & -.07 & $-.14^{*}$ & -.11 \\
5. ITI & & & & & -.01 & .11 \\
6. SRE & & & & & $.49^{* *}$ \\
7. English Mindset & & & & & & \\
\hline
\end{tabular}

Note. ${ }^{*} p<.05$ (2-tailed), $* * p<.01$ (2-tailed). For all correlations between categorical variables (gender, achievement, LD status, English stream), Spearman's rho was used to calculate the strength of the relationship. For all other variables, the Pearson product moment correlation was used.

\section{Main Analyses}

I used univariate analyses of variance (ANOVA) to examine differences in offline variables by school stream, gender, LD status, and achievement. Based on the analyses of past research in this area (Baird et al., 2009; Blackwell et al., 2007), the alpha level used to identify significant group differences was $p<.05$. Given the exploratory nature of this research, the alpha level reflects my desire to avoid type-II error (Jaeger \& Halliday, 1998). I calculated effect sizes for each comparison using Cohen's $d$ index to determine the magnitude of any significant differences. The index specifies that a $d$ of .20 is a small effect, a $d$ of .50 is a moderate effect, and a $d$ above .80 is a large effect (Cohen, 1988). I met all assumptions prior to running ANOVAs, and no outliers were present in the data.

Offline variables and stream. To test the null hypothesis that no differences exist between students in the university and college streams in English on offline variables, I conducted a series of ANOVAs. The tests revealed a significant difference in selfregulatory efficacy between students in the university stream and college stream, $F(1$, $226)=10.18, p=.005, d=.43$. Students in the university stream had more confidence in their general ability to self-regulate than their peers in the college stream. According to the Cohen's $d$ index, the difference in self-regulatory efficacy between students in the university and college English streams was small. The tests also revealed a significant difference in English mindset between students in the university stream and college stream, $F(1,228)=7.59, p<.05, d=.36$. Students in the university stream had a mindset in English that was more consistent with the growth mindset when compared to their peers in the college stream. According to the Cohen's $d$ index, the difference in English mindset between students in the university and college English streams was also small (Cohen, 1988). To further explore English mindset, I performed separate ANOVAs for the three items that represent reading mindset in English and the three items that represent writing mindset in English. The tests revealed a significant difference in reading mindset in English between students in the university stream and the college stream, $F(1,228)=14.09, p<.001, d=.50$. According to the Cohen's $d$ index, the 
difference in reading mindset between students in the university and college English streams was moderate (Cohen, 1988). No significant differences were revealed on implicit theories of intelligence, $F(1,228)=1.47, p=.23, d=.16$, and writing mindset in English, $F(1,228)=.39, p=.53, d=.09$, between students in the university and college streams. Besides self-regulatory efficacy and English mindset, students in the two streams did not differ on offline variables. A further investigation did reveal a significant difference between students in the two streams in reading mindset in English, but not in writing mindset in English. Effect sizes for non-significant relationships between students in the university and college streams in English were trivial (Cohen, 1988).

Offline variables and LD status. To test the null hypothesis that no differences exist on offline variables between students who reported that they had been identified with LD and those who had not, I conducted a series of ANOVAs. The tests revealed a significant difference in implicit theories of intelligence between students who reported that they had been identified with a learning disability and those who had not, $F(1,228)$ $=4.36, p=.038, d=.37$. Participants who reported they had been identified with a learning disability were more likely to endorse an incremental theory of intelligence, consistent with the growth mindset, when compared to participants who had never been identified with LD. According to the Cohen's $d$ index, the difference in implicit theories of intelligence between students with and without LD was small (Cohen, 1988). I found no statistically significant differences between LD and non-LD students on selfregulatory efficacy, $F(1,226)=2.51, p=.114, d=.27$, or English mindset, $F(1,228)=$ $.032, p=.858, d=.04$. After separating English mindset into reading and writing, there were still no differences between LD and non-LD students on reading mindset in English, $F(1,228)=.179, p=.673, d=.08$, and writing mindset in English, $F(1,228)=.022, p$ $=.882, d=.03$. Besides the difference in implicit theories of intelligence, participants with and without LD did not differ on other offline variables. Effect sizes for all nonsignificant comparisons ranged from trivial to small (Cohen, 1988).

Offline variables and achievement. To test the null hypothesis that no differences exist between students with four levels of student achievement on offline variables, researcher conducted a multivariate analysis of variance (MANOVA). I found a statistically significant difference in offline variables based on the level of achievement a student self-reported, $F(12,585)=5.08, p<.001$; Wilk's $\Lambda=.769$, partial $\eta^{2}=.08$. I conducted ANOVAs for each dependent variable as follow-up tests to the MANOVA.

The ANOVA for the self-regulatory efficacy scores was significant, $F(3,224)=$ 15.12, $p<.001$, partial $\eta^{2}=.17$. A Tukey's Post-Hoc test revealed that mean scores for self-regulatory efficacy were significantly different between students at the A and B levels $(p=.001, d=.57)$, the A and C levels $(p<.001, d=1.04)$, and the A and D levels $(p<.001, d=1.32)$. According to the Cohen's $d$ index, the difference in self-regulatory efficacy between students in the A and B grade ranges was moderate. The differences in self-regulatory efficacy between students at the A and C as well as the A and D levels were large (Cohen, 1988). No significant differences in mean scores of self-regulatory efficacy occurred between students at the $\mathrm{B}$ and $\mathrm{C}$ levels $(p=.18, d=.38)$, the $\mathrm{B}$ and $\mathrm{D}$ levels $(p=.08, d=.64)$, or the $\mathrm{C}$ and D levels $(p=.78, d=.30)$. Participants who reported they had received a midterm grade in the A range in English had more confidence in their general ability to self-regulate than participants at all other 
achievement levels. No differences in self-regulatory efficacy were revealed between other grade levels. Effect sizes for non-significant relationships in self-regulatory efficacy between achievement groups ranged from small to moderate (Cohen, 1988).

The ANOVA of the English mindset scores was also significant, $F(3,226)=7.12, p$ $<.001$, partial $\eta^{2}=.09$. A Tukey's Post-Hoc test revealed that mean scores for English mindset were significantly different between students at the $\mathrm{A}$ and $\mathrm{C}$ levels $(p<.001, d=$ .75 ) and the A and D levels $(p=.015, d=.80)$. According to the Cohen's $d$ index, the difference in English mindset between students in the $\mathrm{A}$ and $\mathrm{C}$ grade ranges was moderate, and the difference between students at the A and D levels was large (Cohen, 1988). No significant differences in mean scores of English mindset occurred between students at the $\mathrm{A}$ and B levels $(p=.10, d=.36)$, the $\mathrm{B}$ and $\mathrm{C}$ levels $(p=.25, d=.33)$, the $\mathrm{B}$ and $\mathrm{D}$ levels $(p=.43, d=.39)$, or the $\mathrm{C}$ and $\mathrm{D}$ levels $(p=.995, d=.07)$. Participants who had received a midterm grade in the A range had a mindset in English that was more consistent with the growth mindset when compared to their peers in who received a midterm grade in the $\mathrm{C}$ or D range. Effect sizes for non-significant relationships in English mindset between achievement levels ranged from trivial to small (Cohen, 1988).

To further explore English mindset, I performed separate ANOVAs for the three items that represent reading mindset in English and the three items that represent writing mindset in English. The ANOVA of the reading mindset in English scores was significant, $F(3,226)=9.76, p<.001$, partial $\eta^{2}=.11$. A Tukey's Post-Hoc test revealed that mean scores for reading mindset in English were significantly different between students at the A and C levels $(p<.001, d=.90)$, A and D levels $(p=.013, d=.77)$, and the $\mathrm{B}$ and $\mathrm{C}$ levels $(p=.03, d=.51)$. According to the Cohen's $d$ index, the difference in reading mindset in English between students in the $\mathrm{A}$ and $\mathrm{C}$ grade ranges was large, and the difference between students at the A and D as well as the B and C levels was moderate (Cohen, 1988). No significant differences in mean scores of reading mindset in English occurred between students at the A and B levels $(p=.12, d=.35)$, the B and D levels $(p=.37, d=.41)$, or the $\mathrm{C}$ and $\mathrm{D}$ levels $(p=.99, d=.09)$. Effect sizes for nonsignificant relationships in reading mindset between achievement levels ranged from trivial to small (Cohen, 1988). The ANOVAs based on the writing mindset score, $F$ (3, $226)=1.52, p=.21$, partial $\eta^{2}=.02$, and the implicit theories of intelligence score, $F(3$, 226) $=2.60, p=.05$, partial $\eta^{2}=.03$, were all non-significant.

Besides self-regulatory efficacy and English mindset, students did not differ on offline variables when I made comparisons based on their grades in English. A further investigation did reveal a significant difference between students in both streams in reading mindset in English, but not in writing mindset in English.

Offline variables and gender. To test the null hypothesis that no differences exist between females and males on offline variables, I conducted a series of ANOVAs. The tests revealed significant differences in self-regulatory efficacy between females and males, $F(1,226)=4.23, p=.041, d=.27$, with females reporting higher scores. According to the Cohen's $d$ index, the difference in self-regulatory efficacy between females and males was small (Cohen, 1988). I found no significant differences in implicit theories of intelligence, $F(1,228)=1.24, p=.27, d=.15$, or English mindset, $F(1,228)$ $=3.19, p=.08, d=.24$, between females and males. Effect sizes for non-significant 
relationships in offline variables between females and males ranged from trivial to small (Cohen, 1988). Despite no significant difference emerging between females and males in English mindset, I conducted a further analysis separating reading mindset and English and writing mindset in English. A significant difference was found in reading mindset in English between females and males, $F(1,228)=4.09, p=.044, d=.26$, with females reporting higher scores. According to the Cohen's $d$ index, the difference in selfregulatory efficacy between females and males was small (Cohen, 1988). No difference was found between females and males in writing mindset in English, $F(1,228)=.64, p=$ $.42, d=.11$. Females and males differed only in self-regulatory efficacy and reading mindset in English, with females reporting higher scores on both variables.

\section{Discussion}

What students believe about their ability to self-regulate may be a variable that merits further study regarding its effect on student performance and academic stream. The examination of offline variables by school stream is an extension of past research on offline variables of students in secondary school (e.g., Baird et al., 2009). The present study extends previous research by reporting that students who are in courses designed for university-bound students are more confident in their ability to self-regulate than their peers in courses designed for college-bound students. The present study also replicates the findings of existing research on self-regulatory efficacy and achievement (Klassen, 2010; Pajares, 2007), in which the researchers found that students who have higher grades have higher self-regulatory efficacy than their peers with lower grades. The fact that I found no significant differences between students with and without LD in selfregulatory efficacy is inconsistent with past research that has found higher self-regulatory efficacy in students without LD when compared to their LD peers (Baird et al., 2009; Klassen, 2010). It is possible that the students who reported having LD in the present study have received targeted support to improve their self-regulation, and therefore that their self-regulatory efficacy is no different from their non-LD peers. In a review of the literature on the self-efficacy beliefs of students with LD, Klassen (2002) concluded that these students sometimes overestimate their abilities in specific contexts, including writing performance. It is possible that students with LD in the present study overestimated their abilities to self-regulate, leading to the finding that students with LD do not differ in their self-regulatory efficacy when compared to their non-LD peers. It must be kept in mind that the students self-identified as having LD, a procedure not commonly used, but that was necessary in this study due to conditions imposed by the participating school. Finally, the finding that females have higher self-regulatory efficacy than males could be viewed as consistent with past research about females outperforming males in language arts (Williams, 2006). Given this trend, females may have more confidence in their self-regulatory abilities specifically in an English course setting.

The English mindset construct is conceptually consistent with Dweck's (2006) concept of mindset, though with a focus on English-related skills. The distinction between reading and writing mindset in English allowed me to examine more deeply the differences between students in various groups within the present study. After the distinction was made between reading and writing mindset in English, the importance of reading mindset became clear as it relates to school stream, achievement, and gender. In 
past research on mindset, researchers have found that students who endorse a growth mindset typically have higher grades (Blackwell et al., 2007) and that they are less likely to have LD (Baird et al., 2009). Moderate to large effect sizes were found in the present study that support the idea that students with higher grades are more likely to endorse a growth mindset about reading when compared to their lower achieving peers. Students in the university stream also were found to be more likely to endorse a growth mindset in reading than their peers in the college stream with a moderate effect size. The reputed gender gap in literacy between males and females may in part account for females reporting a more growth-oriented mindset in reading than males. It is possible that females may recognize the gender gap and expect to do better in literacy when compared to males. According to the results of the present study, mindset about reading (selfreported) appears to distinguish between academic path, gender, and achievement for students in secondary school, whereas writing mindset does not. Interestingly, I found no differences between students with and without LD on reading mindset, which is inconsistent with past research about mindset and LD (Baird et al., 2009).

Lastly, students in the current study do not appear to be thinking differently about the nature of intelligence based on their gender, achievement, or school stream. The results of the present study do not support differences that have been found between high and low achievers in implicit theories of intelligence (Blackwell et al., 2007), and in fact are in direct contradiction with past research about students with and without LD (Baird et al., 2009). Students with LD in the present study were more likely to endorse an incremental theory of intelligence, consistent with the growth mindset, when compared to their non-LD peers. Again, it is possible that students in the present study with LD (in a school with a strong resource program) have received support from educators that affected the way they think about their disability and their intelligence. Past research that has identified a difference between males and females (e.g., Siegle et al., 2010) and high and low achievers (e.g., Blackwell et al., 2007) based on offline variables has largely been conducted in the United States, and it is possible that differences in findings may be partially a result of a difference in the delivery of education in the two countries. Further research would be necessary to determine whether or not the findings of the current study are representative of data in Canada on this issue.

While the results of the present study do not provide information about implicit messages students may receive from instructors in particular school streams, they do provide a picture of students within each school stream. Belonging to a particular group within the present study does not seem to be related to the way students think about intelligence, although it may be related to the way they conceptualize reading ability. A student's confidence in their abilities, particularly when it comes to self-regulation, also seems to have a relationship with academic path and achievement. These findings suggest that it would be helpful for educators and parents to communicate messages consistent with growth mindset when thinking about reading as an ability. It is important for educators and parents to talk about and teach reading as a skill that can always be improved upon with practice and effort. The findings also suggest that educators and parents should place more emphasis on helping students to develop confidence in their self-regulatory abilities, as this appears to be an important variable in students' achievement, as well as related to the academic stream in which they are enrolled. This 
may involve students' developing self-regulatory strategies and identifying areas of need during SRL in order to improve this process. This emphasis would be most helpful for atrisk students, including those who are performing at a lower level, and those who are in the college-bound stream.

In the present study, the findings are considered within Zimmerman's (2000) model for SRL in the stages that are considered to be offline. These offline variables influence the way a student perceives and understands a task, and likely would also influence the strategies that a student would use to accomplish a task. Endorsing an incremental theory of reading ability, consistent with the growth mindset, would likely lead to a more directed effort toward developing reading skills. A student with more confidence in their ability to self-regulate when in a learning environment would likely take more chances and use more sophisticated learning strategies with a strong belief that they will succeed. In contrast, a student who believes reading is a fixed ability and who has low confidence in their self-regulatory abilities would likely not attempt to improve at reading, and would also use less sophisticated learning strategies with a belief that they will not succeed. An example of a sophisticated learning strategy is re-reading a section of text in order to identify the area of confusion and to better understand the text, whereas a less sophisticated learning strategy is asking a teacher for help when the text becomes confusing. Offline variables may influence the overall success of SRL, and therefore warrant investigation to identify groups that would be at-risk for challenges with SRL. It is important to note that the variables in the present study that are considered to be offline variables related to SRL are viewed within Zimmerman's (2000) model as being attached to the SRL process that involves a learning task. In the present study, these variables are examined independent of a learning task. Despite this separation, I argue that this examination provides valuable insight into group differences on these variables of interest, which can help inform our understanding of SRL with at-risk students.

\section{Limitations}

The present study had several limitations that should be considered when interpreting the findings. Data came from one secondary school in a rural area with an ethnically homogenous sample. This makes it difficult to generalize the findings with confidence to a broader population of secondary students, as the data source was limited. I collected all of the data except stream by self-report, making it difficult to judge whether students provided accurate information, especially about LD status and English grade. Typically, self-report is not used as a methodology for collecting information on LD status (e.g., Baird et al., 2009), and the use of this methodology in the present study may have influenced the results to be inconsistent with past research on LD. Also, data about whether or not students with LD were receiving support was not collected, which challenges the validity of LD status as it was used in the current study. Use of self-report methodology can also pose problems for students when reporting on conceptually abstract terms that require reflection, such as about beliefs or self-efficacy (Karabenick et al., 2007). All of the issues raised in this paragraph are a result of the limitations imposed on me by a school that was in the midst of a job action by the teachers of Ontario. 
The internal reliabilities for both the Learning vs. Performance Goal Preference scale (Dweck, 1999) and the Effort Attribution scale (Dweck \& Leggett, 1988) were poor (.52 for each). Dweck (1999) suggested that the Learning vs. Performance Goal Preference scale shows stronger associations with implicit theories of intelligence when the participant is first given a task to perform, which was not done in this study. Making judgments about behaviours may be difficult when it involves the consideration of the frequency of a behaviour without the opportunity to engage in the behaviour prior to the evaluation, as memory and reflection on past instances of the behaviour can be difficult (Winne \& Perry, 2000; Winne, Jamieson-Noel, \& Muis, 2002). Given the circumstances related to the limitations placed on me by the school as mentioned earlier, I could not provide a task prior to administering the scale. Finally, it is possible that both scales are not as well suited to students of the age group sampled in the present study, who were in their upper years in secondary school. In a study that used the same two scales with students from grades 6-12, the researchers found low internal consistencies (Baird et al., 2009). It is possible that these scales become less valid measures of learning vs. performance goal preference and effort vs. ability attributions for students in upper years. There may be problems with the wording of the questions and both scales are short.

In spite of the limitations, there is merit in the findings about the beliefs and aspirations of students based on their educational stream, given that this is an exploratory study.

\section{Future Research}

The present study was the first to examine offline variables related to SRL across educational streams (i.e., university- vs. college-bound streams), and more research needs to be conducted to investigate possible differences among students in each stream beyond self-regulatory efficacy. A researcher might examine the process a student goes through when making the decision about which stream to enter, and investigate which variables are involved in making this decision. Additionally, future research could compare actual abilities in reading and writing to offline variables within each stream, rather than selfefficacy for these abilities. This would provide a better understanding of the types of students that are typically found in each stream. Future research should also examine offline variables and stream with a modification to make each item subject-specific, as this would allow researchers to determine whether, in fact, students view subjects such as math or science differently than English in each stream. Lastly, a future investigation might examine what factors influence self-regulatory efficacy and self-regulatory abilities in order to help students with less adaptive ratings improve in these abilities.

\section{Conclusion}

The results from the present study suggest the need for further research to replicate the finding that self-regulatory efficacy and reading mindset distinguish students in different educational streams and achievement levels in English. Self-regulatory efficacy and reading mindset fit conceptually within Zimmerman's (2000) model of SRL, and would therefore contribute to the success of a student's SRL. Lower self-regulatory efficacy and a fixed-oriented mindset in reading may be important offline variables 
related to SRL, and appear to be promising areas of focus in interventions for at-risk youth in education. The findings of this exploratory study suggest a need for further research that focuses directly on whether at-risk students demonstrate maladaptive motivation and specifically on their beliefs, goals, and expectations of themselves as learners.

\section{References}

Aronson, J., Fried, C. B., \& Good, C. (2002). Reducing the effects of stereotype threat on African American college students by shaping theories of intelligence. Journal of Experimental Social Psychology, 38, 113-125. doi:10.1006/jesp.2001.1491

Baird, G. L., Scott, W. D., Dearing, E., \& Hamill, S. K. (2009). Cognitive self-regulation in youth with and without learning disabilities: Academic self-efficacy, theories of intelligence, learning vs. performance goal preferences, and effort attributions. Journal of Social and Clinical Psychology, 28, 1-908. doi:10.1521/jscp.2009.28.7.881

Berg, D. H. (2001). Exploring depressive symptoms in school children. (Unpublished master's Thesis). Queen's University, Kingston, Ontario, Canada.

Blackwell, L. S., Trzesniewski, K. H., \& Dweck, C. S. (2007). Implicit theories of intelligence predict achievement across an adolescent transition: A longitudinal study and an intervention. Child Development, 78, 246-263. doi:10.1111/j.1467-8624.2007.00995.x

Chen, J. A., \& Pajares, F. (2010). Implicit theories of ability of grade 6 science students: Relation to epistemological beliefs and academic motivation and achievement in science. Contemporary Educational Psychology, 35, 75-87. doi:10.1016/j.cedpsych.2009.10.003

Cohen, J. (1988). Statistical power analysis for the behavioral sciences (2nd ed.). Hillsdale, NJ: Lawrence Erlbaum Associates.

Cury, F., Da Fonseca, D., Zahn, I., \& Elliot, A. (2007). Implicit theories and IQ test performance: A sequential meditational analysis. Journal of Experimental Social Psychology, 44, 783-791. doi:10.1016/j.jesp.2007.07.003

Davis, J. L., Burnette, J. L., Allison, S. T., \& Stone, H. (2011). Against the odds: Academic underdogs benefit from incremental theories. Social Psychology Education, 14, 331-346. doi:10.1007/s11218-010-9147-6

DeLuca, C., Hutchinson, N. L., deLugt, J. S., Beyer, W., Thornton, A., Versnel, J., Chin, P., \& Munby, H. (2010). Learning in the workplace: Fostering resilience in disengaged youth. Work: A Journal of Prevention, Assessment, and Rehabilitation, 36, 305-319. doi:10.3233/WOR-2010-1032

Dupeyrat, C., \& Marine, C. (2005). Implicit theories of intelligence, goal orientation, cognitive engagement, and achievement: A test of Dweck's model with returning to school adults. Contemporary Educational Psychology, 30, 43-59. doi:10.1016/j.cedpsych.2004.01.007

Dweck, C. S. (1999). Self-theories: Their role in motivation, personality, and development. Philadelphia, PA: Psychology Press.

Dweck, C. S. (2006). Mindset: The new psychology of success. New York: Random House. Dweck, C. S., \& Leggett, E. L. (1988). A social-cognitive approach to motivation and personality. Psychological Review, 95, 256-273. doi:10.1037/0033-295X.95.2.256

Effeney, G., Carroll, A., \& Bahr, N. (2013). Self-regulated learning: Key strategies and their sources in a sample of adolescent males. Australian Journal of Educational \& Developmental Psychology, 13, 58-74. 
Elliot, A. J., \& McGregor, H. A. (2001). A 2 x 2 achievement goals framework. Journal of Personality and Social Psychology, 80, 501-519. doi:10.1037/0022-3514.80.3.501

Hallahan, D. P., Pullen, P. C., \& Ward, D. (2013). A brief history of the field of learning disabilities. In H. L. Swanson, K. H. Harris \& S. Graham (Eds.), Handbook of learning disabilities (pp. 15-32). New York, NY: Guilford Publications.

Hammer, D., \& Elby, A. (2002). On the form of a personal epistemology. In B. K. Hofer \& P. R. Pintrich (Eds.), Personal epistemology: The psychology of beliefs about knowledge and knowing (pp. 169-190). Mahwah, NJ: Erlbaum.

Hofmann, W., Schmeichel, B. J., \& Baddeley, A. D. (2012). Executive functions and self- regulation. Trends in Cognitive Sciences, 16, 174-180. doi:10.1016/j.tics.2012.01.006

Hong, Y., Dweck, C. S., Chiu, C., Lin, D. M., \& Wan, W. (1999). Implicit theories, attributions, and coping: A meaning system approach. Journal of Personality and Social Psychology, 77, 588599. doi:10.1037/0022-3514.77.3.588

Huang, C. (2012). Discriminant and criterion-related validity of achievement goals in predicting academic achievement: A meta-analysis. Journal of Educational Psychology, 104, 48-73. doi:10.1037/a0026223

Hutchinson, N. L. (2014). Inclusion of exceptional learners in Canadian schools: A practical handbook for teachers (4th ed.). Toronto, ON: Pearson Canada.

Ilkowska, M., \& Engle, R. W. (2010). Working memory capacity and self-regulation. In R. H. Hoyle (Ed.), Handbook of personality and self-regulation (pp. 265-290). Malden, MA: Blackwell Publishing Ltd.

Jaeger, R. G., \& Halliday, T. R. (1998). On confirmatory versus exploratory research. Herpetologica, $54,64-66$.

Jehng, J. C., Johnson, S. D., \& Anderson, R. C. (1993). Schooling and students' epistemological beliefs about learning. Contemporary Educational Psychology, 18, 23-35. doi:10.1006/ceps.1993.1004

Karabenick, S. A., Woolley, M. E., Friedel, J. M., Ammon, B. V., Blazevski, B., Bonney, C. R., .. . Kelly, K. L. (2007). Cognitive processing of self-report items in educational research: Do they think what we mean? Educational Psychologist, 42, 139-151. doi:10.1080/00461520701416231

Klassen, R. (2002). A question of calibration: A review of the self-efficacy beliefs of students with learning disabilities. Learning Disability Quarterly, 25, 88-102. doi:10.2307/1511276

Klassen, R. N. (2010). Confidence to manage learning: The self-efficacy for self-regulated learning of adolescents with learning disabilities. Learning Disabilities Quarterly, 33, 19-30.

Klassen, R. M., Krawchuk, L. L., \& Rajani, S. (2008). Academic procrastination of undergraduates: Low self-efficacy to self-regulate predicts higher levels of procrastination. Contemporary Educational Psychology, 33, 915-931. doi:10.1016/j.cedpsych.2007.07.001

Leondari, A., \& Gialamas, V. (2002). Implicit theories, goal orientations, and perceived competence: Impact on students' achievement behavior. Psychology in the Schools, 39, 279-291. doi:10.1002/pits.10035

Ommundsen, Y. (2006). Pupils' self-regulation in physical education: The role of motivational climates and differential achievement goals. European Physical Education Review, 12, 289315. doi:10.1177/1356336X06069275

Ontario Ministry of Education. (2001). Special Education: A Guide for Educators. 2001. Toronto, ON: Queen's Printer for Ontario. 
Ontario Ministry of Education. (2004). The Individual Education Plan (IEP): A Resource Guide. 2004. Toronto, ON: Queen's Printer for Ontario.

Ontario Ministry of Education. (2007). The Ontario Curriculum, Grades 11 and 12: English. 2007. Toronto, ON: Queen's Printer for Ontario.

Ontario Ministry of Education. (2010). Growing success: Assessment, evaluation, and reporting in Ontario schools. Toronto, ON: Queen's Printer for Ontario.

Ontario Ministry of Education. (2011). Ontario Schools, Kindergarten to Grade 12: Policy and program Requirements. Toronto, ON: Queen's Printer for Ontario.

Pajares, F. (2007). Motivational role of self-efficacy beliefs in self-regulated learning. In B. J. Zimmerman \& D. H. Schunk (Eds.), Motivation and self-regulated learning: Theory, research, and applications (pp. 111-140). New York, NY: Erlbaum.

Pintrich, P. R., \& Schunk, D. H. (2002). Motivation in education: Theory, research, and applications (2nd ed.). Upper Saddle River, NJ: Merrill Prentice Hall.

Rattan, A., Good, C., \& Dweck, C. S. (2012). "It's ok-Not everyone can be good at math": Instructors with an entity theory comfort (and demotivate) students. Journal of Experimental Social Psychology, 48, 731-737. doi:10.1016/j.jesp.2011.12.012

Schraw, G. (2010). Measuring self-regulation in computer-based learning environments. Educational Psychologist, 45, 258-266. doi:10.1080/00461520.2010.515936

Siegle, D., Rubenstein, L. D., Pollard, E., \& Romey, E. (2010). Exploring the relationship of college freshmen honors students' effort and ability attribution, interest, and implicit theory of intelligence with perceived ability. Gifted Child Quarterly, 54, 92-101. doi:10.1177/0016986209355975

Stanovich, K. E. (2005). The future of a mistake: Will discrepancy measurement continue to make the learning disabilities field a pseudoscience? Learning Disability Quarterly, 28, 103-106.

Stipek, D., \& Gralinski, J. H. (1996). Children's beliefs about intelligence and school performance. Journal of Educational Psychology, 88, 397-407. doi:10.1037/0022-0663.88.3.397

Trautwein, U., \& Ludtke, O. (2007a). Predicting global and topic-specific certainty beliefs: Domainspecificity and the role of the academic environment. British Journal of Educational Psychology, 77, 907-934. doi:10.1348/000709906X169012

Trautwein, U., \& Ludtke, O. (2007b). Epistemological beliefs, school achievement, and college major: A large-scale, longitudinal study on the impact of certainty beliefs. Contemporary Educational Psychology, 32, 348-366. doi:10.1016/j.cedpsych.2005.11.003

Tweed, R. G., \& Lehman, D. R. (2002). Learning considered within a cultural context: Confucian and Socratic approaches. American Psychologist, 57, 89-99. doi:10.1037/0003-066X.57.2.89.

Usher, E. L., \& Pajares, F. (2008). Self-efficacy for self-regulated learning: A validation study. Educational and Psychological Measurement, 68, 443-463. doi:10.1177/0013164407308475

Wang, Q., \& Ng, F. F. (2012). Chinese students' implicit theories of intelligence and school performance: Implications for their approach to schoolwork. Personality and Individual Differences, 52, 930-935. doi:10.1016/j.paid.2012.01.024

Williams, B. T. (2006). Girl power in a digital world: Considering the complexity of gender, literacy, and technology. Journal of Adolescent \& Adult Literacy, 50, 300-307. doi:10.1598/JAAL.50

Winne, P., Jamieson-Noel, D., \& Muis, K. (2002). Methodological issues and advances in researching tactics, strategies, and self-regulated learning. In P. R. Pintrich \& M. L. Maehr (Eds.), Advances in motivation and achievement: New directions in measures and methods (pp. 121156). Amsterdam, Netherlands: JAI-Elsevier. 
Winne, P., \& Perry, N. E. (2000). Measuring self-regulated learning. In M. Boekaerts, P. Pintrich, \& M. Zeidner (Eds.), Handbook of self-regulation (pp. 531-566). San Diego, CA: Academic.

Yeager, D. S., \& Dweck, C. S. (2012). Mindsets that promote resilience: When students believe that personal characteristics can be developed. Educational Psychologist, 47, 302-314. doi:10.1080/00461520.2012.722805

Zimmerman, B. J. (2000). Attainment of self-regulation: A social cognitive perspective. In M. Boekaerts, P. Pintrich, \& M. Zeidner (Eds.), Handbook of self-regulation, research, and applications (pp. 13-39). Orlando, FL: Academic Press.

Zimmerman, B. J. (2008). Investigating self-regulation and motivation: Historical background, methodological developments, and future prospects. American Educational Research Journal, 45, 166-183. doi:10.3102/0002831207312909

Zimmerman, B.J., Bandura, A., \& Martinez-Pons, M. (1992). Self-motivation for academic attainment: The role of self-efficacy beliefs and personal goal-setting. American Educational Research Journal, 29, 663-676. doi:10.3102/00028312029003663

\section{Author's Note}

Correspondence concerning this article should be addressed to Ian A. Matheson, Faculty of Education, Queen's University, 511 Union Street, Kingston, ON, Canada K7M 5R7. Email: ian.matheson@queensu.ca 